\title{
Discriminated avoidance conditioning: CS function during avoidance acquisition and maintenance ${ }^{1}$
}

GERALD B. BIEDERMAN

UNIVERSITY OF TORONTO

In a preliminary study the role of a compound CS consisting of white noise and light was found to change from the most effective stimulus in the acquisition phase of discriminated avoidance conditioning to the least effective in the maintenance phase when compared with the CS of light or the CS of white noise.

Avoidance conditioning has been found to occur rapidly under the condition of low intensity shock during shaping and training (D'Amato, Fazzaro, \& Etkin, 1967). The CS was a compound of white noise and light. While there is little doubt that the $.2 \mathrm{~mA}$ shock and the early use of discontinuous shock (.2 sec on, 2 sec off) in shaping and training produced the significant increment in conditioning, the role of the type of CS used was not evaluated. Previous experiments using moderate shock (1 $\mathrm{mA}$ ) have revealed that white noise or the compound of white noise and light, in comparison to light alone, facilitated avoidance conditioning (D'Amato, Keller, \& DiCara, 1964; Biederman, 1967b). D'Amato et al (1967) found that high intensity shock (5 $\mathrm{mA}$ ) produced significantly more avoidance after approximately 600 training trials had elapsed; thus the role of shock intensity was found to change during the acquisition and maintenance phases of avoidance conditioning.

The usual strategy in overcoming the resistance to conditioning that rats show in the discriminated bar press avoidance situation has been to manipulate shock variables. The present paper reports preliminary data on the role of the CS during each phase of discriminated avoidance conditioning (cf., Biederman, D'Amato, \& Keller, 1964).

\section{Method}

Subjects were 18 male Wistar rats approximately 90-120 days old, supplied by Canadian Research Animal Farms, Bradford, Ontario.

The apparatus was the same as used in previous experiments (Biederman, 1967a, b), consisting of two Grason-Stadler operant conditioning chambers, each independently controlled by standard programming equipment.

Subjects were randomly assigned to one of three CS groups: (1) Noise, in which the CS was $80 \mathrm{~dB}$ white noise (2) Light, in which the CS was the illumination of three pilot lights located over the response lever; and (3) Compound, in which both white noise and the illumination of the pilot lights served as CS. Each $\mathrm{S}$ remained in the assigned CS group throughout the experiment. The remaining procedure was essentially that of D'Amato et al (1967). On Day 1 the escape response was shaped (when necessary) for 60 trials. Shock intensity was adjusted to the lowest value possible for each $\mathrm{S}(.2-.4 \mathrm{~mA})$; the shock was shifted from continuous to discontinuous shock (.2 sec on, 2 sec off) as soon as possible. On Day 2 all Ss were given 400 avoidance trials at a discontinuous shock of .2 $\mathrm{mA}$. On Days 3 and 4 , Ss were given 400 additional trials per day with half the $\mathrm{Ss}$ in each CS group randomly assigned to a shock level of .2 $\mathrm{mA}$ and half assigned to a shock intensity of $4 \mathrm{~mA}$. CS-US interval was $5 \mathrm{sec}$; the intertrial interval was VI $45 \mathrm{sec}$.

\section{Results and Discussion}

The response measure employed in this experiment was the mean percentage of avoidance responses on the last 300 trials on each of Days 2-4 (cf., D'Amato, Keller, \& Biederman, 1965). During the first 400 training trials, a familiar pattern of avoidance emerged with respect to the type of CS used; Compound and Noise conditions produced significantly more avoidance than did Light $(F=4.12, p<.05)$ (D'Amato et al, 1964; Biederman, 1967b). The data from Day 2 are shown in Fig. 1.

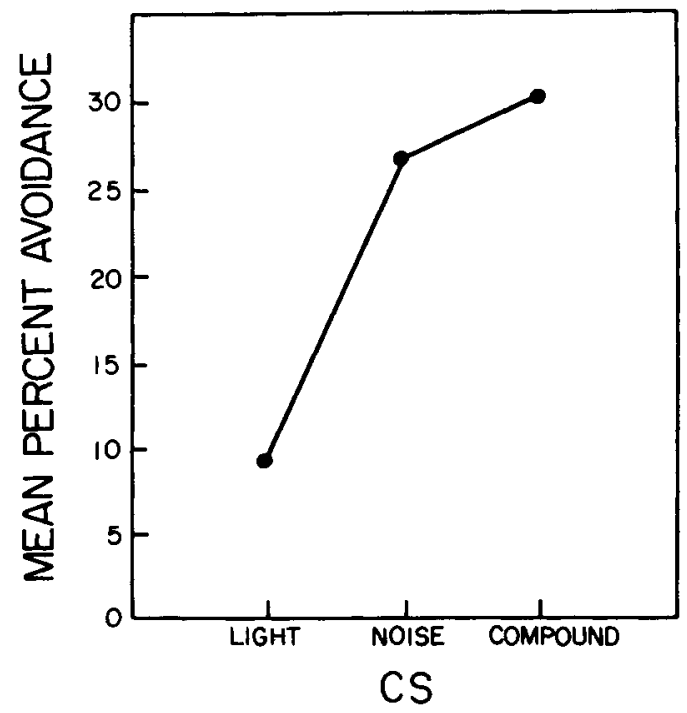

Fig. 1. Mean percentage avoidance on last 300 trials of Day 2 , as a function of CS Group. 


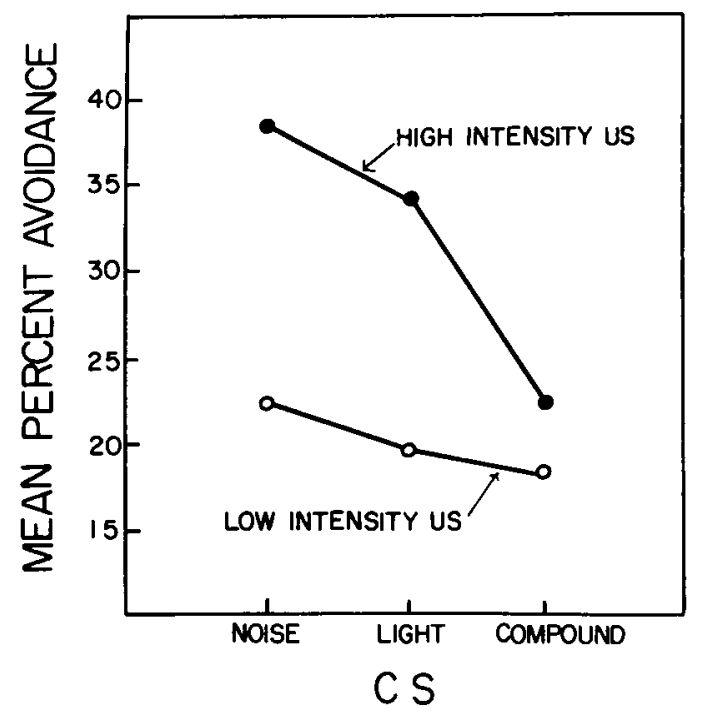

Fig. 2. Mean percentage avoidance on last 300 trials of Day 3 and Day 4 respectively, as a function of shock intensity and CS Group.

The data from Days 3 and 4 present a quite different picture of the relationship between type of CS and percentage of avoidance, as indicated in Fig. 2. During what may be designated as the maintenance phase of avoidance conditioning, the Compound CS was replaced as the optimal avoidance stimulus by Noise. What is more surprising, Light CS was superior to Compound in avoidance maintenance. Figure 2 supports the finding of D'Amato et al (1967) that high intensity shock facilitates the maintenance of avoidance behavior. The data of Days 3 and 4 may only be considered as a preliminary indication of the complex role that a compound stimulus may play in avoidance conditioning since analysis of variance did not reveal significant main effects because of the small sample size. Stimuli and Shock main effects accounted for most of the variance.

Attention may provide an explanation for the difference in stimulus function in acquisition and maintenance. High fear may restrict S's attention to the noise component of the compound stimulus during acquisition. As training progresses to the maintenance phase the likelihood of shifts in attention may increase as fear declines, disrupting the performance of Ss under the compound stimulus. The assumption here is that noise is the more effective CS during avoidance acquisition, and any decrease in attending to this component will of necessity decrease performance.

References

BIEDERMAN, G. B. Discriminated avoidance conditioning as a function of duration of intertrial interval and type of shock. Psychon. Sci, 1967a, 9, 155-156.

BIEDERMAN, G. B. Discriminated avoidance conditioning: Stimulus function in shaping and training. Psychon. Sci, 1967b, 9, 263-264.

BIEDERMAN, G. B., D'AMATO, M. R., \& KELLER, D. M. Facilitation of discriminated avoidance learning by dissociation of CS and manipulandum. Psychon. Sci, 1964, 1, 229-230.

D'AMATO, M. R., FAZZARO, J., \& ETKIN, M. Discriminated bar-press avoidance maintenance and extinction in rats as a function of shock intensity. J. comp. physiol. Psychol, 1967, 63, 351-354.

D'AMATO, M. R., KELLER, D., \& BIEDERMAN, G. Discriminated avoidance learning as a function of parameters of discontinuous shock. J. exp. Psychol., 1965, 70, 543-548.

D'AMATO, M. R., KELLER, D., \& DICARA, L. Facilitation of discriminated avoidance learning by discontinuous shock. $J$. comp. physiol. Psychol., 1964, 58, 344-349.

Note

1. This research was supported by Grant 185 from the Canadian National Research Council, and by Grant 106 from the Ontario Mental Health Foundation. The experiment was performed by Miss M. Archer, G. Heighington, and Miss B. Macfadyen. 